\title{
Mental Health Status in Dry Eye Disease - a Case Control Study
}

\author{
Luxmi Singh, Vijay Pratap Singh, Swati Yadav and Pragati Garg \\ Department of Ophthalmology, Era's Lucknow Medical College, Lucknow, Uttar Pradesh, India
}

S tudies suggest that dry eye disease (DED) can have a considerable impact on visual function, daily activities, social and physical functioning, workplace productivity, direct and indirect cost of the disease, and quality of life. Some psychological and mental health issues such as sleep disorders, anxiety, depression and mood disturbances have also been shown to be triggering factors for DED, thus indicating a mutually reversible relationship between DED and mental health status. Mental health and DED have a possible relationship which has not been duly explored. This study was conducted on patients attending the Department of Ophthalmology, Era's Lucknow Medical College, Lucknow, India. Informed consent was obtained from all study participants. Personal and family history and ocular symptoms, with emphasis on symptoms associated with DED, were recorded. Complete ocular examination was done based on ocular symptoms: they were graded on ocular surface disease index (OSDI), Schirmer's test (without anaesthetic) and tear-film break-up time (TBUT) test. All the patients were subjected to general health questionnaire (GHQ)-12 to evaluate and categorise mental health status. The study group consisted of 125 patients diagnosed with DED and an equal number of demographically matched individuals with no symptoms of DED as controls. The mean age of patients with DED was $34.58 \pm 0.31$ years, whereas the mean age of controls was $34.61 \pm 3.38$ years. The majority of DED cases (69.6\%) and controls (64.0\%) were female. There was a statistically significant difference between mean values for Schirmer's test and TBUT between the DED and control groups ( $p<0.001)$. Mean OSDI values were significantly higher in cases $(58.21 \pm 19.77)$ as compared to that of controls (23.55 \pm 7.69$)$ ( $p<0.001)$. Using GHQ inventory, a total of $57 / 125$ DED cases $(45.6 \%)$ and $16 / 125$ controls $(12.8 \%)$ had scores of $>4$, indicating emotional disorders or poor psychological wellbeing. For all these disorders, the prevalence was significantly higher in patients with DED compared to controls $(p<0.05)$. Among patients with mild, mild to moderate and moderate to severe DED, prevalence of a psychiatric disorder was $23 \%, 97 \%$ and $100 \%$, respectively (based on Schirmer's test). DED was associated with psychiatric disorders with a decrease in mental health state as the severity of DED increased.

\section{Keywords}

Mental health, ocular surface disease index, OSDI, Schirmer's test, GHQ-12

Disclosure: Luxmi Singh, Vijay Pratap Singh, Swati Yadav and Pragati Garg have nothing to disclose in relation to this article.

Review process: Double-blind peer review.

Compliance with Ethics: All procedures were followed in accordance with the responsible committee on human experimentation and with the Helsinki Declaration of 1975 and subsequent revisions. Informed consent was received from the patients involved in this study.

Authorship: All named authors meet the International Committee of Medical Journal Editors (ICMJE) criteria

for authorship of this manuscript, take responsibility for the integrity of the work as a whole, and have given final approval to the version to be published.

open Access: This article is published under the

Creative Commons Attribution Noncommercial

License, which permits any noncommercial

use, distribution, adaptation, and reproduction

provided the original author(s) and source are

given appropriate credit. (c) The Authors 2018.

Received: 16 May 2018

Accepted: 19 July 2018

Citation: European Ophthalmic Review. 2018;12(1):56-9

Corresponding Author: Luxmi Singh, Department of

Ophthalmology, Era's Lucknow Medical College, Lucknow, Uttar Pradesh 226003, India. E: drluxmi@redffmail.com

Funding: No funding was received for

the publication of this article.
Twenty-five percent of patients who visit ophthalmic clinics report symptoms of dry eye and it is one of the most common conditions seen by eye care practitioners. ${ }^{2}$ Approximately two-thirds of patients affected by dry eye disease (DED) are female and elderly, ${ }^{2,3}$ and there is a higher risk in postmenopausal women. ${ }^{4}$ The occurrence of severe forms of DED is reported to increase with age and almost $8 \%$ of women and $4 \%$ of men over the age of 50 years have more severe DED. ${ }^{5,6}$ The prevalence rates of DED have been shown to vary substantially across different geographical regions. ${ }^{7-13}$

Epidemiological studies of Indian populations report prevalence rates of 9.5-370/1,000 for psychiatric disorders. ${ }^{14}$ The chronic discomfort observed in patients with DED may also have a negative impact on other aspects of patient health, such as cognitive processes, mood and mental health. ${ }^{15}$ When quality of life is affected, a patient's psychological wellbeing is also affected, leading to initiation of mental imbalance. Some psychological and mental health issues such as sleep disorders, anxiety, depression and mood disturbances have also shown to be triggering factors for $D E D,{ }^{16,17}$ thus indicating a mutually reversible relationship between DED and mental health status. Additionally, drug intake for mental health disorders may contribute to DED. ${ }^{18}$

In recent years, a number of researchers from western countries have investigated the impact of DED on psychiatric wellbeing in large retrospective epidemiological studies.19,20 These studies, in general, have shown a positive association between DED and psychiatric comorbidities. Incidentally, there are almost no studies from developing countries, particularly India, on this issue. The purpose of the present study is to address the dearth of research on mental health status and DED in developing countries.

\section{Material and methods}

Study participants were split into two groups: those diagnosed with DED and a control group with no diagnosis or symptoms of DED. All observations were conducted at the Department of Ophthalmology, Era's Lucknow Medical College, Lucknow, India. Exclusion criteria included DED due to ocular pathologies, hypertension, diabetes mellitus, dysthyroidism, smoking, any drug intake for more than 3 months and any radiation therapy or surgery in the past 3 months. Users 
Table 1: Demographic profile of study participants

\begin{tabular}{|c|c|c|c|}
\hline Characteristic & DED group $(n=125)$ & Control group $(n=125)$ & $\mathrm{p}$-value \\
\hline $\begin{array}{l}\text { Mean age }+ \text { SD (range) in years } \\
<30 \\
31-40\end{array}$ & $\begin{array}{l}34.58+0.31(26-40) \\
11(8.8 \%) \\
114(91.2 \%)\end{array}$ & $\begin{array}{l}34.61+3.38(26-40) \\
10(8.0 \%) \\
115(92.0 \%)\end{array}$ & $\begin{array}{l}0.955 \\
0.820\end{array}$ \\
\hline $\begin{array}{l}\text { Gender } \\
\text { Male } \\
\text { Female }\end{array}$ & $\begin{array}{l}38(30.4 \%) \\
87(69.6 \%)\end{array}$ & $\begin{array}{l}45(36.0 \%) \\
80(64.0 \%)\end{array}$ & 0.347 \\
\hline
\end{tabular}

$D E D=$ dry eye disease $; S D=$ standard deviation .

Table 2: Dry eye tests - Schirmer's test, TBUT and OSDI

\begin{tabular}{|c|c|c|c|c|c|c|}
\hline \multirow[t]{2}{*}{ Test } & \multicolumn{2}{|c|}{$\begin{array}{l}\text { DED group } \\
(n=125)\end{array}$} & \multicolumn{2}{|c|}{$\begin{array}{l}\text { Control group } \\
(n=125)\end{array}$} & \multicolumn{2}{|c|}{ Statistical significance } \\
\hline & Mean & SD & Mean & SD & $\mathrm{T}$ & p-value \\
\hline Schirmer's test & 10.26 & 3.12 & 23.68 & 6.25 & -30.40 & $<0.001$ \\
\hline TBUT & 7.05 & 2.40 & 14.59 & 1.72 & -40.41 & $<0.001$ \\
\hline OSDI & 58.21 & 19.77 & 23.55 & 7.69 & 18.27 & $<0.001$ \\
\hline
\end{tabular}

$D E D=$ dry eye disease; $O S D I=$ ocular surface disease index; $S D=$ standard deviation; $T$ = Student's $t$ test; $T$ TBUT = tear-film break-up time

of computers and smart phones for more than 8 hours daily were also excluded as device use can contribute to the development of DED and may confound the study. ${ }^{21,22}$ A detailed history regarding ocular symptoms, with emphasis on symptoms associated with DED, was obtained from all subjects included in the study. Informed consent was obtained from all study participants. Tear production grading and ocular symptoms were measured using three tests: Schirmer's test, tear-film break-up time (TBUT) test and ocular surface disease index (OSDI). ${ }^{23,24}$

\section{Schirmer's test}

A specialised Schirmer's strip was prepared from Whatman ${ }^{\mathrm{TM}}$ filter paper (GE Healthcare Life Science, Chicago, IL, US) measuring 40x5 mm, graded 0-35 mm. A $5 \mathrm{~mm}$ strip was folded and placed in the lower fornix at the junction of medial $2 / 3$ and lateral $1 / 3$, and time noted. Extent of wetting of the strip was noted after 5 minutes. Wetting of less than $15 \mathrm{~mm}$ was regarded as effective tear production. Grading of tear production was as follows: normal $=\geq 15 \mathrm{~mm}$, mild = 9-14 mm, moderate $=4-8 \mathrm{~mm}$, severe $=\leq 4 \mathrm{~mm}$.

\section{Tear-film break-up time test}

Fluorescein strip was used to stain the eye. The patient was asked to blink three or four times to distribute the dye in conjunctival sac and was then asked to look straight ahead and not to blink. The eye was scanned using slit lamp under cobalt blue light; the first area of tear film rupture, manifested by the appearance of a black island within the green film of fluorescein, was noted. TBUT was the time, in seconds, between the last blink and the appearance of a dry spot on cornea categorised as: normal $=>10.0$ seconds, mild $=6.1-10.0$ seconds, moderate $=3.1-6.0$ seconds, severe $=\leq 3$ seconds.

\section{Ocular surface disease index}

OSDI measures the severity of DED (normal, mild to moderate and moderate to severe) based on a 12-item patient-reported outcome questionnaire. Grading is as follows: normal $=0-12$ points, mild to moderate $=13-31$ points, moderate to severe $=32-100$ points. ${ }^{25}$

$$
\mathrm{OSDI}=\frac{\text { (sum of scores) } \times 25}{\text { number of questions answered }}
$$

\section{Evaluation and categorisation of mental health status}

All study participants were subjected to general health questionnaire (GHQ)-12 to evaluate and categorise mental health status. ${ }^{26,27} \mathrm{~A}$ GHQ-12 score of $\leq 3$ is considered normal, and these patients would require no further evaluation. A score of $\geq 4$ is considered abnormal and requires further patient evaluation for psychiatric disorders.

\section{Statistical analysis}

The statistical analysis was done using SPSS (Statistical Package for Social Sciences) Version 15.0 statistical analysis software. The values were represented in number (\%) and mean \pm standard deviation (SD). Student's t-test was performed to test the significance of two mean values. An a priori benchmark of statistical significance was set at $p<0.05$, with $p<0.01$ being highly significant and $p<0.001$ very highly significant.

\section{Results}

A total of 125 patients fulfilled the inclusion criteria and had a diagnosis of DED. Another 125 healthy volunteers were recruited as a control arm. The mean age was $34.58 \pm 0.31$ years in the DED group and $34.61 \pm 3.38$ years in the control group. There was no significant difference in age between the two groups ( $p=0.820)$. The majority of participants in the DED group, as well as the control group, were female (69.6\% and $64.0 \%$, respectively). There was no significant difference between the groups with respect to gender ( $p=0.347$ ). Baseline characteristics are provided in Table 1 .

Mean values for Schirmer's test and TBUT were $10.26 \pm 3.12$ and $7.05 \pm 2.40$, respectively in the DED group, and $23.68 \pm 6.25$ and $14.59 \pm 1.72$, respectively in the control group. Statistically, for both the parameters, there was a significant difference between the two groups $(p<0.001)$. Mean OSDI values were significantly higher in the DED group $(58.21 \pm 19.77)$ compared to that of the control group $(23.55 \pm 7.69 ; \mathrm{p}<0.001)$ (Table 2).

As per OSDI, only 6 (4.8\%) participants in the DED group were in the normal range, 103 (82.4\%) had mild to moderate OSDI grade and $16(12.8 \%)$ had moderate to severe OSDI grade. In the control group, a total of $121(96.8 \%)$ had normal and only 4 (3.2\%) had mild to moderate 
Table 3: Comparison of ocular surface disease index grade between cases and controls

\begin{tabular}{|l|l|l|}
\hline OSDI Grade & Cases $(n=125)$ & Controls $(n=125)$ \\
\hline$n(\%)$ & $n(\%)$ \\
\hline Normal & $6(4.8)$ & $121(96.8)$ \\
\hline Mild to moderate & $103(82.4)$ & $4(3.2)$ \\
\hline Moderate to severe & $16(12.8)$ & $0(0.0)$ \\
\hline
\end{tabular}

Table 4: Comparison of mental health status of cases and controls (based on general health questionnaire-12 assessment)

\begin{tabular}{|l|l|l|}
\hline GHQ-12 score category & DED group & Control group \\
\hline & $\mathrm{n}(\%)$ & $\mathrm{n}(\%)$ \\
\hline Score $<4$ - no psychiatric illness & $68(54.4)$ & $109(87.2)$ \\
\hline $\begin{array}{l}\text { Score } \geq 4 \text { - positive for emotional } \\
\text { disorders or poor psychological } \\
\text { wellbeing }\end{array}$ & $57(45.6)$ & $16(12.8)$ \\
\hline Mean GHQ \pm SD (range) & $2.90 \pm 2.75$ & $0.98 \pm 1.54$ \\
\hline
\end{tabular}

$D E D=$ dry eye disease; $G H Q=$ general health questionnaire; $S D=$ standard deviation.

OSDI grade. Statistically, there is a significant difference between the two groups with respect to OSDI grade $(p<0.001)$ (Table 3$)$.

Using the GHQ-12 inventory a total of 57/125 participants in the DED group (45.6\%) and 16/125 in the control group (12.8\%) had scores of $>4$, indicating emotional disorders or poor psychological wellbeing $(p<0.001)$ (Table 4). In the DED group, prevalence of psychiatric disorder was $23 \%$ for patients with mild DED, 97\% for those with moderate DED and 100\% for those with severe DED (based on Schirmer's test). The incidence of psychiatric disorders was significantly higher for those with moderate and severe DED as compared to mild $(p<0.001)$.

\section{Discussion}

In the present study, we made an attempt to evaluate the association between psychiatric disorders and the severity of DED. Using Schirmer's test and GHQ-12 to quantify the severity of DED and mental wellbeing, respectively, we found that only $23 \%$ of patients with mild DED experience psychiatric comorbidity, whereas those with moderate and severe DED had a significantly higher risk of psychiatric comorbidity $(97.0 \%$ and $100.0 \%$, respectively). When looking at the DED group as a whole, the results presented here indicate a significantly higher prevalence of psychiatric illness in people with DED compared to healthy controls ( $45.6 \%$ versus $12.8 \%$, respectively). We chose to use the GHQ- 12 as it is a well-known clinical instrument for measuring psychiatric disorders ${ }^{27}$ and is more specific to the needs of study.
In their 2016 study, Szakátset al. evaluated the correlation between Schirmer's score and anxiety and depression indices (using Beck Anxiety Inventory [BAI] and Beck Depression Inventory, respectively); they found a significant inverse correlation between BAI and Schirmer's scores. ${ }^{28}$ Tiskaoglu et al. also found results similar to the present study, with Schirmer's test values being significantly lower in patients diagnosed with depression compared to patients without depression. ${ }^{29}$ However, Labbe et al., who also assessed a correlation of depression score with Schirmer test and TBUT, failed to derive a significant result. ${ }^{30}$ Li et al. also failed to find a significant correlation between depression scores and Schirmer's and TBUT scores. ${ }^{31}$ Additionally, a study by Kim et al. did not yield a significant relationship between depression severity and Schirmer test. ${ }^{32}$ With regards to OSDI scores, Hallak et al. derived similar results to the present study, reporting significantly higher OSDI scores in patients with DED. ${ }^{26}$

One of the main reasons for the different picture in the present study with respect to the relationship between Schirmer's test and incidence of psychiatric illness could be the difference in the method of assessment, as we did not conduct a linear correlation. Another reason could be that the age range of participants in the present study (20-40 years) differed from that of previous studies, which generally included elderly patients. ${ }^{33,34}$ Increased age could mean that psychiatric morbidity is confounded by factors other than DED. Thus, the present study could provide more useful information regarding the psychiatric impact of DED in a relatively younger population. Notwithstanding the difference in pattern and trend of psychiatric morbidities, almost all the previous studies have shown that patients with DED have an increased risk of psychiatric morbidity as compared to their matched controls.

Like other epidemiological studies, where females can account for up to two-thirds of the study population, ${ }^{2-6}$ females made up the majority of participants in the present study. In order to rule out the impact of age and gender, we purposely selected controls with matching age and gender.

\section{Conclusion}

The findings of present study provide useful information regarding psychiatric impact of DED in a relatively young population. This is the first study the authors are aware of to explore this relationship in an Indian population. This study, in general, supports the existing literature that a significant association between DED and psychiatric morbidity burden is present, while at the same time providing some newer information suggesting that the relationship between severity of DED and psychiatric comorbidity should not be viewed as a linear one and should be interpreted in context with the stage of disease, and more so in different life stages of the patient. To validate the findings of our study, further research is recommended in view of the fact that this is probably the first study in an Indian and relatively younger population.
1. O'Brien $P D$, Collum LM. Dry eye: diagnosis and current treatment strategies. Curr Allergy Asthma Rep. 2004:4: 314-9.

2. Lin PY, Tsai SY, Cheng $C Y$, et al. Prevalence of dry eye among an elderly Chinese population in Taiwan: the Shihpai Eye Study. ophthalmology.2003;110:1096-101.

3. Moss SE, Klein R, Klein BE. Prevalence of and risk factors for dry eye syndrome. Arch Ophthalmol. 2000;118:1264-8.

eye syndrome. Arch Ophthalmol. 2000;118:1264-8.
Chia EM, Mitchell P, Rochtchina E, et al. Prevalence and

Chia EM, Mitchell P, Rochtchina E, et al. Prevalence and associations of dry eye syndrome in an older population: the Blue Mountains Eye Study. Clin Experiment Ophthalmol. 2003;31:229-32.

5. Schaumberg DA, Dana R, Buring JE, Sullivan DA. Prevalence of dry eye disease among US men: Estimates from the Physicians Health Studies. Arch Ophthalmol. 2009;127:763-8.

6. Schaumberg DA, Sullivan DA, Buring JE, Dana MR. Prevalence of dry eye syndrome among US women. Am J Ophthalmol. 2003:136;318-26.

7. McCarty CA, Bansal AK, Livingston PM, et al. The epidemiology of dry eye in Melbourne Australia. Ophthalmology.1998:105:1114-9.

8. Lee AJ, Lee J, Saw SM, et al. Prevalence and risk factors associated with dry eye symptoms: a population based study associated with dry eye symptoms: a population

9. Lin PY, Tsai SY, Cheng CY, et al. Prevalence of dry eye among Lin PY, Tsai SY, Cheng CY, et al. Prevalence of dry eye among
an elderly Chinese population in Taiwan: the Shihpai Eye Study Ophthalmology. 2003;110:1096-101.

10. Doughty MJ, Fonn D, Richeter D, et al. A patient questionnaire approach to estimating the prevalence of dry eye symptoms in patients presenting to optometric practices across Canada. Optom Vis Sci. 1997;74:624-31.

11. Shimmura S, Shimazaki J, Tsubota K. Results of a population- based questionnaire on the symptoms and lifestyles associated with dry eye. Cornea. 1999:18:408-11.

12. Gupta SK, Gupta V, Joshi S, Tandon R. Subclinically dry eyes in urban Delhi: an impact of air pollution? Ophthalmologica. 2002;216:368-71.

13. Sahai A, Malik P. Dry Eye: Prevalence and attributable risk factors in a hospital-based population. Ind I Ophthalmol. 2005:53:87-91.

14. Ayaki M, Kawashima M, Negishi K, Tsubota K. High prevalence of sleep and mood disorders in dry eye patients: survey of 1,000 eye clinic visitors. Neuropsychiatr Dis Treat. 2015;11:889-94

15. Yilmaz U, Gokler ME, Unsal A. Dry eye disease and depressionanxiety-stress: A hospital-based case control study in Turkey. Pak J Med Sci. 2015;31:626-31.

16. Yu J, Asche CV, Fairchild CJ. The economic burden of dry eye 
disease in the United States: a decision tree analysis. Cornea. 2011;30:379-87.

17. Math SB, Chandrashekhar CR, Bhugra D. Psychiatric epidemiology in India. Ind I Med Res. 2007;126:183-92.

18. Fine PG. Long-term consequences of chronic pain: mounting evidence for pain as a neurological disease and parallels with other chronic disease states. Pain Med. 2011;12:996-1004.

19. Dibajnia P, Mohammadinia M, Moghadasin M, Amiri MA Tear film break-up time in bipolar disorder. Iran I Psychiatry. 2012;7:191-3.

20. Galor A, Feuer W, Lee DJ, et al. Prevalence and risk factors of dry eye syndrome in a United States veterans affairs population. Am J Ophthalmol. 2011;152:377-84

21. Galor $A$, Feuer W, Lee DJ, et al. Depression, post-traumatic stress disorder, and dry eye syndrome: a study utilizing the national United States Veterans Affairs administrative database. Am J Ophthalmol. 2012;154:340-6.

22. Smiti A, Goel D, Sharma A. Evaluation of the factors which
Contribute to the ocular complaints in computer users. $J$ Clin Diagn Res. 2013;7:331-5.

23. Takahide K, Parker P, Wu M, et al. Use of fluid ventilated, gas permeable sclera lens for management of severe keratoconjunctivitis sicca secondary to chronic graft-versushost disease. Biol Blood Marrow Transplant. 2007;13:1016-21.

24. Stapleton F, Garrett Q, Chan C, Craig JP. The Epidemiology of Dry Eye Disease. In: Chan C (eds). Dry Eye: A practical approach. Heidelberg: Springer-Verlag, 2015:21-9.

25. Miller KL, Watt JG, Mink DR, et al. Minimal clinically important difference for the ocular surface disease index. Arch Ophthalmol. 2010;128:94-101.

26. Hallak JA, Tibrewal S, Jain S. Depressive symptoms in patients with dry eye disease: a case-control study using the beck depression inventory. Cornea. 2015;34:1545-50.

27. Jackson C. The General Health Questionnaire. Occup Med (Lond). 2007:57:79.

28. Szakáts I, Sebestyén M, Németh J, et al. The role of health anxiety and depressive symptoms in dry eye disease. Curr Eye Res. 2016;41:1044-1049.

29. Tiskaoglu NS, YazıCI A, Karlıdere T, et al. Dry eye disease in patients with newly diagnosed depressive disorder. Curr Eye Res. 2017:42:672-6

30. Labbe A, Wang YX, Jie $Y$, et al. Dry eye disease, dry eye symptoms and depression: The Beijing Eye Study. Br J Ophthalmol. 2013;97:1399-403.

31. Li M, Gong L, Sun X, Chapin WJ. Anxiety and depression in patients with dry eye syndrome. Curr Eye Res. 2011; 36:1-7.

32. Kim KW, Han SB, Han ER, et al. Association between depression and dry eye disease in elderly population. Invest Ophthalmo Vis Sci. 2011;52:7954-8.

33. Sözeri-Varma G. Depression in the elderly: clinical features and risk factors. Aging Dis. 2012:3:465-71.

34. Mirowsky J, Ross CE. Age and depression. J Health SOC Behav. 1992;33:187-205. 